Recebido: $31 / 10 / 2018$

Aprovado: 12/12/2018

\title{
A criação de uma Diplomacia Anticomunista no governo Vargas, em 1937
}

Margarida Nepomuceno ${ }^{1}$

Resumo: O interesse em estudar a formação de uma agência anticomunista no governo Vargas, nos momentos que precederam a implantação do Estado Novo, resulta dos meus estudos sobre a política cultural do Brasil na América Latina em torno de um episódio que resultou, em 1935, no rompimento das relações diplomáticas do Uruguai com a Rússia sob a pressão do governo brasileiro. Esse episódio revelou o ativismo de uma diplomacia anticomunista em países da região e da formação de uma agência que atuou junto ao Itamaraty no combate aos comunistas, denominada Serviços de Estudos e Investigações (S.E.I.).

Palavras-chaves: Agencia anticomunista; Estado Novo; América Latina.

Abstract: The interest in studying the formation of an anticommunist agency under the Vargas government, in the moments that preceded the implantation of the Estado Novo comes from my studies on the cultural politics of Brazil in Latin

\footnotetext{
${ }^{1}$ Doutora pelo Programa de Pós-Graduação Integração da América Latina- PROLAM- USP, Pesquisadora Colaboradora do mesmo Programa. Pesquisa a formação de redes de intelectuais na América, a partir do governo de Getúlio Vargas até anos 80.
} 
America around an episode that resulted, in 1935, in the disruption of diplomatic relations with Russia under pressure from the Brazilian government. This episode revealed the activism of an anticommunist diplomacy in countries of the region and the formation of an agency that worked with the Itamaraty in the fight against communists, denominated Services of Studies and Investigations (S.E.I.). Keywords: Anticommunist agency; New State; Latin America.

A constatação de que as legações do Brasil no exterior e as missões diplomáticas brasileiras constituíam verdadeiros "postos de observação" da conjuntura internacional, para orientar as ações do governo em sua política externa, facilitou a criação e organização de uma agência anticomunista no governo Vargas junto ao Ministério das Relações Exteriores. Criada oficialmente em 1937, junto ao Ministério das Relações Exteriores, a agência de Serviços de Estudos e Investigações (S.E.I.) ${ }^{2}$ teve como objetivo central dar suporte à política de combate à oposição, particularmente aos militantes partidários e sindicais e um grande facilitador para que os órgãos do governo monitorassem as conexões dos comunistas brasileiros além das fronteiras do país.

No ano anterior, em 28 de janeiro de 1936, a Conselheira Odette de Carvalho e Souza, funcionária de longa carreira do Ministério das Relações Exteriores, ${ }^{3}$ encaminhou ao ministro José Carlos de Macedo Soares, um memorial contendo as principais argumentações para a instituição dos Serviços de Estudos e Investigações. Em sua exposição de motivos, a conselheira justificava que a criação dessa agência seria uma forma propositiva do Itamaraty colaborar na obra conjunta do governo Vargas “ (...) de prevenção e repressão contra o comunismo, servindo-se de suas representações diplomáticas e consulares no estrangeiro com o intuito de providenciar (...) trabalhos de investigação, prestar informações ou esclarecimentos” sobre a atividade de brasileiros,

\footnotetext{
${ }^{2}$ Nota: utilizarei a sigla S.E.I. ao referir-me ao Serviço de Estudos e Investigações.

${ }^{3}$ Odette de Carvalho e Souza, carioca de nascimento, iniciou sua carreira no MRE em 1931, como Conselheira técnica governamental da XV Conferência Internacional do Trabalho, em Genebra. Seguiramse participações como arquivista da Delegação do Brasil na Conferência do Desarmamento, em 1932; conselheira técnica da XV e XVII Conferências Internacionais do Trabalho, em 1932 e 1933; prestou serviços como adida no gabinete do ministro Macedo Soares, em 1934: fez parte da comitiva do presidente Vargas na viagem que realizou ao Prata ( Argentina e Uruguai ) em 1935;represetante do Brasil na Intente Internacional de Genebra, em 1934. Em 1935, foi contratada pelo MRE destacando-se por exercer a representação do Brasil em vários eventos políticos internacionais. Participou das conferências panamericanas como membro da representação do Brasil, em especial, na Conferência de Paz, pouco antes da II Guerra, em Buenos Aires. AHDI- Rio de Janeiro. Fichário dos servidores do MRE do governo Vargas. Sobre Odette de Carvalho e Souza: fichas 01 e 02.
}

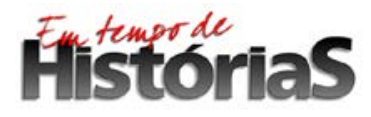


que na condição de exilados políticos ou de partidários da doutrina socialista representassem alguma ameaça aos rumos do governo” (AHDI-RJ, Memorial,1937: 1-3).

De acordo com as principais linhas argumentativas apresentadas nesse memorial, os S.E.I. teria a função de extirpar a ameaça vermelha no Brasil e impedir que os vários agrupamentos de esquerda da época conduzissem a ação política dos intelectuais brasileiros. Esses serviços estariam ligados a vários órgãos do governo, especificamente, aos ministérios da Justiça, aos ministérios militares (Guerra, Marinha e Aeronáutica) e à direção da Polícia Federal, e funcionariam como uma agência anticomunista de informação. Nesse memorial, Odette de Carvalho sublinha as atividades já articuladas pelo Serviço de Estudos e Investigações (S.E.I.) em funcionamento experimental desde início de $1934 .{ }^{4}$ Além de esse serviço constituir-se em um suporte fundamental da política de combate ao comunismo, o Memorial revela o propósito doutrinário e educativo de preparar os agentes do governo munindo-os de ferramentas para entender a lógica do inimigo na sua complexidade. Isso implicava estudar a doutrina marxista e conhecer as estratégias da propaganda bolchevique; procurar entender a malha ou a rede de relações entre os membros e simpatizantes do partido, dentro e fora do país, e como eles se relacionavam. Aos órgãos da Polícia Civil e da Polícia Federal caberia a investigação propriamente dita, e ao Ministério da Justiça e ao Itamaraty, as ferramentas e suporte jurídico e institucional necessários, comprovadamente eficientes em ocasiões anteriores, conforme descrição no Memorial. (AHDI, 1937:2).

Os principais pontos da doutrina anticomunista, adotada pelo governo Vargas, que deveriam nortear, justificar e motivar a criação do S.E.I. alertam inicialmente, para “o caráter internacionalista” do comunismo "e o seu princípio de revolução mundial, que exigiria, segundo sua relatora, que a luta anti-bolchevique deveria ser empreendida no terreno internacional. Todos os países deveriam se unir contra a direção central da Internacional Comunista, o Komintern. No Brasil, esse empreendimento político internacional só poderia ser dirigido pelo Itamaraty, uma vez que as representações internacionais do Brasil configuravam uma sólida estrutura que nenhum outro ministério poderia oferecer.

Outro ponto refere-se à adesão da Rússia à Sociedade das Nações, por meio da qual aquele país estaria operando internacionalmente e se imiscuindo na política interna

\footnotetext{
${ }^{4}$ AHDI-RJ. Memorial 500.1. Lata 980. Maço 15604, pgs 1-5. 
dos países para alcançar seu objetivo de estender o comunismo além-fronteiras. O Itamaraty e a sua estrutura representativa em países do mundo teria a seu dispor postos de observação que poderiam

“fornecer (...) dados e informações preciosos sobre a acção (sic), as tácticas e as palavras de ordem lançadas por Moscou para estender ao mundo inteiro a sua obra nefasta de destruição. Conhecendo, assim, a obra do inimigo, mais fácil será precavermo-nos, prevenirmo-nos e combate-lo”(AHDI, 1937:1-5).

Um terceiro pronto revela especial cuidado em relação à interferência Russa no Brasil, sobretudo durante as insurreições de 27 de novembro de 1935, episódio que para o governo fora orientado, financiado e dirigido por estrangeiros ligados ao comando central do PC soviético, episódio que recorreremos mais adiante. Como prevenir novos levantes? E três ações eram sugeridas:

-evitar a entrada no Brasil de elementos "extremistas e indesejáveis negando-lhes o visto no passaporte, ou dificultando sua aquisição aos indivíduos suspeitos”;

- facilitar a ação policial, fornecendo dados sobre indivíduos presos ou suspeitos que já se encontravam no Brasil, auxiliando a polícia na localização policial, fossem brasileiros ou estrangeiros;

- prevenir a entrada ao país de elementos suspeitos, ou a introdução de material de propaganda, ou de demais materiais tais como armas, etc.

O quarto item dizia respeito ao auxílio que as representações diplomáticas ou consulares poderiam oferecer nos processos de expulsão dos estrangeiros considerados “extremistas indesejáveis”. Isso poderia ser realizado através da criação de uma rede de informações com os governos de fronteiras para obter informações sobre entradas clandestinas de armas no país. E mais, as representações diplomáticas poderiam utilizar: “(...) a facilidade oferecida pela rede institucional do Itamaraty com organismos internacionais de combate ao comunismo para reunir e transmitir essas informações às autoridades diretamente autorizadas à ação de repressão, que seriam a Política Federal e os ministérios militares. Essas seriam atribuições também das representações do Brasil no Exterior, de onde deveriam chegar também informações sobre as articulações dos militantes comunistas brasileiros fora do país”(AHDI-RJ, 1937:4). 
Nesse mesmo memorial, Odette de Carvalho e Souza, trouxe uma relação de serviços “relevantes” já prestados pelo Itamaraty na obra de prevenção e repressão ao comunismo, em períodos anteriores a $1936 .{ }^{5}$ Alguns desses itens são citados a seguir:

- o Itamaraty influenciou a ação do governo brasileiro de não reconhecimento dos sovietes e junto ao Conselho Federal de Comércio Exterior. Não permitiu que o Brasil aprovasse o estabelecimento do Yuyamtorg, uma representação do comercio da Rússia no mundo, em terras brasileiras, a mesma que existia no Uruguai cuja implantação no país foi permitida pelo governo. A argumentação para essa negativa era de que "longe de favorecer o nosso comércio exterior constituiria, unicamente, um importante e perigoso foco de ação moscovita no Brasil e no continente”. E mais...

- o Itamaraty teria colaborado "nos trabalhos de elaboração da Lei de Segurança Nacional (...)”, colaboração essa elogiada , segundo Odette de Carvalho, pelo próprio relator do projeto na Câmara, deputado Henrique Bayna;

- o Itamaraty denunciou as finalidades da ANL - Aliança Nacional Libertadora, fundada em 1934- aos poderes constituídos do estado brasileiro, enviando a todos os governadores e ministérios, comprovação desde a Rússia, das ligações do movimento do PC com o líder Luiz Carlos Prestes.

- o mesmo órgão dedicou-se à minuciosa tarefa de registrar e informar a movimentação dos comunistas facilitando a que o governo impedisse as manobras da ANL durante a insurreição comunista de 1935, prendendo as principais lideranças do movimento, dentre elas o ex-deputado alemão no Brasil, Harry Berguer. Foi o Itamaraty com seus serviços atentos de rastreamento, o responsável por entregar para a Polícia Federal a sua localização.

Expostos os princípios de uma doutrina que foi adotada durante o governo do presidente Getúlio Vargas, bem como as atividades até então desenvolvidas pelo

\footnotetext{
${ }^{5}$ O S.E.I , segundo o projeto de portaria assinado pelo Ministro das Relações Exteriores em 1937, estaria em atividade ( ainda que em caráter experimental), desde 1934. AHDI-RJ. Doc 352.345. Maço 15.604. Lata 980. M 500.1.p2.
}

\section{Filistororias}


Itamaraty em alguns dos episódios mais marcantes da história do comunismo no Brasil, são apresentadas sugestões de uma estrutura mínima de funcionamento do S.E.I. junto ao Itamaraty: uma sala própria e duas funcionárias datilógrafas. A proposta inicial é que esses serviços ficassem interligados ao Departamento dos Negócios Políticos e Diplomáticos, portanto, diretamente subordinados ao gabinete do Ministério das Relações Exteriores (MRE) devido ao caráter confidencial e às vezes sigiloso de suas atividades. (CF. AHDI-RJ. Maço 15.604. Lata 980. Mem. 500.1 p 5).

\section{Portaria criando os S.E.Is.}

Em $1^{\circ}$ de fevereiro de 1937, o ministro interino das Relações Exteriores, Francisco Negrão de Lima, apresenta as linhas gerais do projeto de criação dos S.E.Is, a serem criados dentro da estrutura oferecida pelo MRE através das legações no exterior ${ }^{6}$, obedecendo aos critérios e princípios, já mencionados, da doutrina anticomunista. Dentre as atividades, os S.E.Is seriam destinados ao

"estudo da doutrina marxista, dos meios de propaganda e luta contra o comunismo, estudo das questões sociais e tudo quanto se relacione com o problema anticomunista no Brasil, devendo manter com os Ministérios Militares, com o Ministério da Justiça e com a Polícia do Distrito Federal uma estreita ligação na obra de prevenção contra o extremismo subversivo"(AHDI, 1937:2)

Deveriam funcionar sob a chefia de um funcionário com estudos especializados sobre o assunto e da confiança imediata do ministro de Estado. Seriam condições essenciais, qualidades como competência técnica, eficiência comprovada, e ação rápida. Os S.E.Is estariam ligados à Secretaria Geral e sob o comando direto do Chefe dos Negócios Políticos e Diplomáticos do Itamaraty.

Na verdade, aquele momento era de legalização do SEI, provavelmente diante dos outros órgãos do Estado, uma vez que esses serviços estavam sendo realizados, segundo Odette de Carvalho, desde janeiro de 1936, em caráter experimental, sob a sua própria coordenação juntamente com o Ministro de Estado José Carlos de Macedo Soares, exchefe do Departamento dos Negócios Políticos e Diplomáticos do Itamaraty e do ministro Hildebrando Accioly. Entretanto, como os próprios relatórios comprovam, os S.E.Is já estavam atuando desde 1934, rastreando a movimentação do Partido Comunista.

\footnotetext{
${ }^{6}$ AHDI-RJ. Memorial 500.01. Projeto de Portaria criando os S.E.Is. do Itamaraty.Doc. 352.345. Maço 15.604. lata 980. Pgs 1-3.
} 
Ficaria sob a atribuição de uma secretária os serviços reservados, sigilosos do S.E.I para organizar um arquivo com todos os dados e fichários de interesse. Essa funcionária perceberia um salário de 200 mil réis. ${ }^{7}$

\section{Pavilhão anticomunista: comemoração das realizações da "Revolução" e do Estado Novo}

Ao final do primeiro ano de Estado Novo, o governo Vargas realizou uma grande exposição, mostrando à opinião pública nacional e estrangeira, as realizações de seu governo e a obra monumental de um país forte e moderno e, especialmente, que não se deixava persuadir pela ideologia marxista. Junto à Exposição Nacional, composta de vários pavilhões ministeriais, Getúlio erigiu um, especificamente, denominado de pavilhão da Exposição Anticomunista. As articulações comprovadas pela documentação dão conta de que o Pavilhão da Exposição Anticomunista fora articulada meses antes e que ficara sob a direção do Ministério da Justiça. No ítem 4, do relatório da primeira reunião organizativa dos eventos, subscrito por Odette de Carvalho, que exponho a seguir, ela se refere à exposição anticomunista como tendo sido "idealizada para comemorar o primeiro aniversário do Estado Novo" ${ }^{\text {. }}$

Nesse memorando - de circulação reservada - destinado ao chefe de gabinete do MRE, assinado por Odette Carvalho e Souza, constava o resumo das primeiras decisões organizativas da “Exposição Anti-comunista” e a exposição de “ Propaganda do Estado Novo”, a começar pela representação dos poderes na comissão de organização. Esta seria constituída por representante das Três Armas Militares, do Ministério da Agricultura, do Trabalho, da Fazenda, representante da Polícia Civil e pela própria Odette de Carvalho, como representante do Ministério das Relações Exteriores.

A data estava definida. Seriam inauguradas ambas as exposições no mesmo dia e local: 10 de dezembro de 1938 nas dependências do Teatro Municipal do Rio de Janeiro. O ítem 5 destinou-se a explicar em linhas gerais em torno das quais consistiam as duas exposições. Para a exposição anticomunista seria trabalhado um acervo composto por um amplo material nacional que mostrava a propaganda do movimento comunista do Brasil,

\footnotetext{
${ }^{7}$ Nota da autora: não me pareceu pela descrição dos relatórios que deveria ser uma funcionária com especiais qualidades, uma vez que à ela eram atribuídas funções apenas técnicas, de relevância burocrática. Diferente do perfil de Odette de Carvalho e Souza, funcionária de carreira do Ministério das Relações Exteriores, para quem coube, desde a primeira hora a articulação entre os ministérios.

${ }^{8}$ AHDI-RJ. Memorando ( reservado), 511.1 de 15 de setembro de 1936. p 1-2.
}

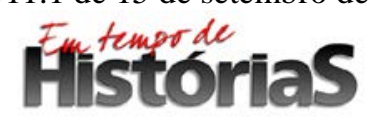


com imagens e armas apreendidas durante as batidas policiais; objetos da Revolução de 35, folhetos e boletins extremistas, literatura anticomunista, fotografias, e outros materiais. Seriam expostos também materiais veiculados ou produzidos fora do Brasil que mostravam a luta universal contra o comunismo, constando de mapas, diagramas, frases e imagens de apreensões inéditas.

Para os pavilhões que deveriam representar os ministérios do governo Vargas e suas realizações desde o início do governo, em 1930, pensou-se em fazer uma “demonstração do trabalho construtor do regime nacional, constante de grandes ampliações das principais obras públicas executadas pelo Governo e das que se encontravam em andamento; apresentação fotográfica do trabalho educacional e social realizado pelo regime; divisão do material exposto por secções ministeriais, sob a forma mais sugestiva; demonstrações gráficas com diagramas, curvas, índices, etc. do desenvolvimento da vida nacional sob os aspectos econômicos, comercial, industrial, financeiro, educacional e social; e apresentação dos principais dados estatísticos em cartazes artísticos e fotografias sugestivas”. (AHDI, 1936:2)

Lourival Fontes, diretor do DIP- Departamento de Imprensa e Propaganda, um dos homens fortes de Getúlio, seria o responsável por elaborar, por alinhavar o material de propaganda obtido junto aos ministérios: as maquetes, fotos, gráficos, etc. Suas orientações ficaram claras desde o início: a exposição de informações do governo deveriam ser objetivas e didáticas pois seriam vistas pelo grande público, bem como teriam que ter caráter temporal comparativo, entre 1930 e 1938, para mostrar as mudanças ocorridas em todas as áreas do país durante o governo Vargas, até aquele momento.

Ao ministro da Justiça, naquele momento, Francisco Negrão de Lima, ${ }^{9}$ caberia a responsabilidade pela organização da exposição de propaganda anticomunista. A colaboração do MRE foi reconhecida uma vez que sairia daquele ministério a maioria dos documentos e “conhecimentos especializados de seu representante”, numa referência a equipe de Odette de Carvalho e Souza, o petit comitê formado para essa exposição ficaria assim constituído: pelo ministro da Justiça acima mencionado; por Álvaro Vieira Pinto ${ }^{10}$

\footnotetext{
${ }^{9}$ Francisco Negrão de Lima estava exercendo nesse momento a função de ministro interino. Ele seria o ministro da Justiça de Vargas, em seu segundo governo.

10 Álvaro Vieira Pinto teve uma carreira na politica educacional do país, especificamente no ensino da Filosofia. Começou em 1934 na Ação Integralista (Plinio Salgado), com Negrão de Lima esteve no $1^{\circ}$ e $2^{\circ}$ governos de Getúlio. Em seguida, passou pelo ISEB, Instituto Superior de Estudos Brasileiros criado em 1955, exilando-se após o seu fechamento, em 13 de abril de 1964. Em 1956, a convite do embaixador no
} 
que na ocasião secretariava do ministro da Justiça; por representantes da Política Civil e por Odette de Carvalho, representante do MRE, presença indispensável, conforme deu a entender o Ministro da Justiça, por seus serviços prestados nessa área. (AHDI, 1936:3).

O exemplo a seguir, conforme relata Odette de Carvalho é a Itália e a Alemanha cujas propagandas são elaboradas como contrapartida ou como reação às políticas anticomunistas. Para Odette, se na Itália e Alemanha "os troféus do regime são troféus da luta contra o flagelo rubro”, no Brasil de Vargas isso não ocorria. A propaganda sobre as realizações do governo não se apresentavam em estreita relação com às políticas anticomunistas e caberia “à imaginação dos organizadores da exposição anticomunista estabelecer (...) dentro do nosso ambiente, uma ligação lógica entre as duas partes da exposição”. (AHDI, 1936:3).

Caberia ao ministro da Justiça e seu comitê, a elaboração de sugestões para os vários setores do governo participantes para que essa correlação fosse estabelecida.

Qual teria sido a motivação que levou o governo Vargas e realizar as duas exposições conjuntamente, mostrando de um lado as realizações de seu governo até aquele momento e a sua visão de acirramento de combate ao comunismo em terras brasileiras.

Pela mobilização de todos os ministérios públicos, aliada à objetiva preocupação de "passar a limpo" as benfeitorias realizadas pelo governo, desde a chamada revolução de 30 até aquele momento, fica claro que o país que se quer mostrar tem capacidade e desenvolvimento comprovados para assumir uma nova posição no mundo, com preeminência marcante em relação aos países da região. Essa pretensão pode ser traduzida na colaboração do Ministério das Relações Exteriores, na secção de Limites, que comporia um dos pavilhões da mostra sobre o Estado Novo denominada de “O Brasil no Mundo”, contendo as informações de todos os tratados celebrados entre Brasil e países latino americanos, de 1930 até 1938, definindo os limites territoriais do Brasil. Toda a documentação comprobatória dessas decisões era exibida através de convenções e tratados celebrados em múltiplas ocasiões. No mapa moldado em madeira, as cores representavam a natureza desses acordos que poderiam ser políticos, econômicos e culturais. No mesmo mapa figuram pontos correspondentes às representações do Brasil no mundo, desde os consulados até os escritórios de representação comerciais. A política

Paraguai, o ex-ministro de Getúlio, Negrão de Lima, ministrou aulas na cátedra de Filosofia, na Universidade do Paraguai e na Universidade Colombiana.

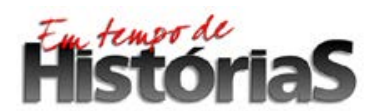


americanista de Getúlio Vargas revelou-se na exposição de painéis com informações fornecidas pela União Pan-americana, escritório administrativo das Conferências Panamericanas, com todas as adesões, ratificações, proposituras de autoria do Brasil durante os encontros internacionais desde 1930 até aquela data. Deveria constar como material nobre da exposição, as políticas de cooperação intelectual, recém-inauguradas por Vargas, em vários lugares do mundo, bem como os livros publicados de autores brasileiros, ilustrativos da cultura e erudição dos brasileiros. O MRE forneceria igualmente, através de material de imprensa, a visão dos países sobre o Brasil mostrando a projeção do país no mundo, em suas várias áreas. ${ }^{11}$

Até fichários pessoais de comunistas brasileiros, sindicalistas e políticos, expostos como criminosos, e demais documentos dos partidos comunistas - referentes à organização, propaganda e educação do partido -, coletados desde o exterior, constavam da exposição que tinha como fundamento reafirmar a doutrina anticomunista do governo Vargas.

A preocupação de Lourival Fontes de expor com clareza dados e informações sobre os feitos do governo parece ter surtido efeito. Carlos Lacerda, em artigo com o mesmo título da exposição, considerou que o evento marcaria o ciclo de oito anos do governo Vargas, que se iniciara em 1930, e que cumpriria com seus objetivos de apresentar em traços essenciais as mudanças que estavam se processando no país: “Através de gráficos de fácil leitura, de abundante documentação fotográfica, de eloquente e simples demonstração, a exposição coloca ao alcance do homem da rua a síntese de um período de realizações e esforços”. Para ele, a Exposição significava um balanço das condições e possibilidades da União e ao mesmo tempo era uma renovação de compromisso do chefe do governo. Getúlio estaria selando um novo pacto com a Nação (LACERDA, Carlos. O Observador Econômico e Financeiro. Edição 36, 1939. P 57).

Umas das peças chave de propaganda anticomunista em circulação na Exposição anticomunista foi justamente um artigo de Carlos Lacerda, naquele momento com 25 anos, na condição de recém-desligado da sessão da Juventude do Partido Comunista. Segundo João Pinheiro Neto, em “Bons e Maus Mineiros e outros brasileiros”(Neto, Rio de Janeiro. Ed. Mauá:1996) Lacerda teria recebido um convite do governo para escrever

\footnotetext{
${ }^{11}$ AHDI-RJ. Memorando assinado por Odette de Carvalho e Souza (Memo 511.1) de 16 de setembro de 1938 ao chefe de gabinete do MRE.
}

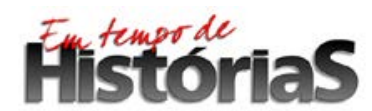


o histórico do Partido Comunista para aquela ocasião. Depois de um primeiro momento de recusa, e de certa mobilização que envolveu o diretor da revista "O Observador Econômico”, Otávio Malta, e membros do Partido Comunista Brasileiro, como Astrogildo Pereira, o artigo de Carlos Lacerda com um longo histórico do Partido Comunista Brasileiro foi finalmente publicado em janeiro de 1939 na revista de Otávio Malta, sem constar, entretanto, a assinatura do autor. Para Astrogildo Pereira era preferível o olhar de um "ex-comunista” escrevendo sobre o comunismo do que um anticomunista. O artigo de Lacerda, segundo Pinheiro Neto, foi editado e distribuído amplamente pelo governo ao público durante a realização da Exposição Anticomunista ${ }^{12}$. Talvez o nome de Lacerda não tivesse sido incluído uma vez que fotos suas foram exibidas na própria exposição em reunião com outros militantes, segundo ainda o próprio João Pinheiro (Pinheiro,1996:195). Lacerda utilizou material apreendido pela Polícia após os levantes de 35 e seu artigo revelava as críticas severas dirigidas a Luís Carlos Prestes pelo próprio PC. Referia-se também a uma suposta interferência da legação russa em Montevidéu para a criação da Aliança Nacional Libertadora o que representava uma grave intromissão de uma nação estrangeira em assuntos internos do Brasil (CF. Pinheiro, 1996:195). Não se sabe ao certo até que ponto seu texto foi alterado, mas Lacerda demonstra com seu testemunho a confiança no país de Vargas, pós 10 de novembro de 1937 e cumpre uma função que o governo, por não dominar toda a complexidade de ação dos comunistas do Brasil não conseguia explicar, que era fornecer uma visão ampla sobre a trajetória recente dos comunistas no Brasil. Ao final do texto, escreve Carlos Lacerda: “O povo acompanhou com interesse a demonstração anticomunista efetuada em pavilhão especial da Exposição Nacional. Um grande mapa mundi assinalava os países onde o Partido Comunista é legal, ilegal ou semilegal. Numerosos esquemas figuravam a organização burocrática da Internacional comunista com suas respectivas seções nacionais. Grande cópia de livros e material subversivo inclusive reproduções fotográficas, grandemente ampliadas, de anteprojeto de constituição elaborado pelos comunistas no Brasil, figuravam na exposição como peças de alto valor documentário” (Pinheiro, 1996: 190).

\footnotetext{
${ }^{12}$ Essa afirmação nos leva a crer que a Exposição Nacional, iniciada em 10 de dezembro de 1938, avançou o ano de 1939, pois foi nesse ano que o artigo de Carlos Lacerda foi impresso no catálogo que por sua vez, consta ter sido distribuído durante a Exposição do governo de Getúlio.
} 
A mostra apresentava cópias de documentos de reuniões realizadas pelas células do partido, de documentos pessoais de militantes, do levante fracassado de 1935, da Guerra Civil Espanhola, etc.

\section{Ruídos diplomáticos: o Brasil queria ser uma Itália ou Alemanha ... nunca uma Espanha}

Em pleno transcurso da Guerra Civil Espanhola (1936-1939) e de grande comoção internacional, o Brasil queria demonstrar que as mudanças promovidas desde a Revolução de 30, pelo presidente Getúlio Vargas não levariam o país na direção tomada pela Espanha, com domínio de um governo de vertente socialista (a Frente Popular) e de “consequente caos”, conforme julgavam setores do governo brasileiro.

Tal era a propaganda anticomunista desferida contra países de governos de esquerda que o embaixador da Espanha no Brasil envia um memorando em 23 de dezembro de 1938 desqualificando o tratamento do governo brasileiro na exposição ao referir-se à Espanha. Episódio esse que trouxe constrangimentos entre as partes e que rendeu farta troca de ofícios. O embaixador da Espanha no Brasil envia um ofício ao MRE criticando e denunciando como não autênticas as informações fornecidas pelo governo brasileiro sobre a guerra Civil Espanhola. Acusa o embaixador, entre várias coisas, que os espanhóis residentes no Brasil e que se empenharam na organização da campanha Ayuda a la España Republicana, constituída pela colônia espanhola, são definidos como apoiadores dos comunistas. Esclarece o embaixador:

El pueblo español, que sufre la evidencia más dura de su heroica historia, no merece este trato tan injusto (...). Los esfuerzos titânicos realizados por la República para estabelecer el orden perturbado por el levantamento fascista, merecen mas respecto. (AHDI-RJ, ofício 18009, 23/12/1938:2)

Dias antes, em 20 de dezembro de 1938, em pleno curso da exposição anticomunista, o Ministro do Estado das Relações Externas recebe um memorando $\left(\mathrm{n}^{\mathrm{o}}\right.$ 500) dando conta de que o encarregado dos Negócios da Espanha no Brasil denunciava a falsidade das informações do governo brasileiro sobre o governo espanhol solicitando que as informações da Espanha fossem retiradas da exposição, uma vez que mostravam uma tentativa tendenciosa e organizada pela envenenar a opinião pública, atribuindo ao governo espanhol atos infundados de barbárie.(Cf. AHDI-RJ, lata 980. 473/ 501.1). Esse episódio gerou um trânsito intenso de ofícios entre o governo brasileiro e a representação espanhola no Brasil.

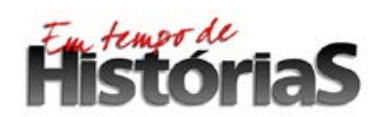


Entre os anos 30 e 40, o cenário regional encontrava os países tentando, cada um à sua maneira, sair da crise econômica que havia assolado o mundo a partir de 1929. De um lado, uma movimentação social de grandes proporções agitava o cenário político e de outro, os governos, buscando saídas de auto proteção e estabilidade de governo. Um dos resultados convergentes de proximidade entre os países foi a adoção de medidas de repressão semelhantes e de proteção entre os governos contra seus opositores, de troca de informações não somente entre as polícias políticas mas entre as chancelarias, para impedir, cercear, vigiar e ate mesmo prender ou extraditar políticos e intelectuais que opunham resistências aos regimes autoritários implantados em vários países da América Latina (Nepomuceno, Banco de Teses USP, 2015).

No caso das relações de Brasil e Uruguai, combate aos subversivos, segundo a historiadora Ana Maria Rodriguez Ayçagüer $(2008,101)$ foi um dos cinco pontos que resumiu a agenda bilateral, estritamente política, assinada em 1930 pelos dois países. Esse acordo implicou não mais em meras recomendações ou prisões de opositores de ambos os lados, mas no rompimento das relações do Uruguai com a Rússia, por pressão do governo brasileiro. A alegação do Brasil é de que a Rússia, que tinha amplos acordos comerciais com o Uruguai, estava ajudando o partido comunista brasileiro na organização dos levantes de 1935. Mesmo sem comprovação convincente, a pressão do governo brasileiro levou o Uruguai, contra a sua vontade, mas em nome dos pactos entre países americanos, a romper as relações comerciais durante muitos meses com a Rússia. Inaugurava-se naquele momento, dentro do governo Vargas, a atuação ativista de uma diplomacia voltada para consecução de políticas anticomunistas.

Poderíamos dizer que na década de 30, o governo Getúlio Vargas esmerou-se em criar modelos específicos de atuação da diplomacia brasileira. Se por um lado promoveu desde 1934 reformas no Ministério das Relações Exteriores, criando um forte fluxo de cooperação cultural com países da América Latina, através do que chamamos de Diplomacia Cultural, tema ao qual procuro desenvolver durante toda minha pesquisa de doutorado, concluída em 2015 (Nepomuceno. São Paulo, Banco Teses USP, 2015) por outro, criou com os mesmos países pactos de defesa nacional, acordos para o combate efetivo dos opositores implantando políticas de reconhecimento e combate efetivo aos comunistas. A Agência Anticomunista é um exemplo de uma rede formada por diplomatas, políticos, governos vizinhos, além de profissionais da máquina burocrática do governo Vargas para concretização desse pacto.

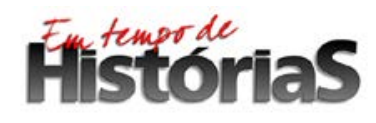

(PPGHIS/UnB) No. 33, Brasília, Ago - Dez 2018 ISSN 2316-1191 


\section{Referências bibliográficas}

AHDI-RJ. Ficha catalográfica dos diplomatas do MRE . Sobre a diplomata Odete de Carvalho e Souza: fichas 01 e 02 .

AHDI-RJ. Maço 500.01. Doc. 352.345. Maço 15.604. lata 980. Pgs 1-3. Projeto de Portaria criando os S.E.Is. do Itamaraty, em 01 de fev. de 1937.

AHDI-RJ. Memorial sobre a necessidade de criação do S.E.I. encaminhado ao ministro Macedo Soares e por Odette de Carvalho e Souza. 28 de jan. de1937.p 1-3.

AHDI-RJ. Memorando ( reservado), Reuniões Preparatórias para a Exposição Anticomunista. 511.1 de 15 de setembro de 1936. p 1-2.

AHDI-RJ, ofício 18009, do Embaixador Espanhol no Brasil contra o tratamento do Brasil ao governo Republicano da Espanha. 23de dez de 1938, p 2.

AHDI-RJ, lata 980. 473/ maço 501.1. Encarregado dos Negócios do governo Espanhol no Brasil pede que se retire as afirmações sobre a Espanha circuladas no transcurso da Exposição Nacional, 20 de dez de 1938.

AHDI-RJ. Memorando assinado por Odette de Carvalho e Souza (Memo 511.1) de 16 de setembro de 1938 ao chefe de gabinete do MRE, constando as instruções para a grande Exposição Nacional, de dezembro do mesmo ano.

LACERDA, Carlos. A Exposição anti-comunista. Revista Observador Econômico e Financeiro. Ed. 36. Pg. (127-213).

NEGRÃO, João Henrique Botteri. Selvagens e Incendiários. O Discurso anticomunista do governo Vargas. São Paulo. Associação Ed. Humanitas. Universidade de São Paulo. 2005.

NEPOMUCENO, M.M.C. A Missão Cultural Brasileira no Uruguai. A Construção de um modelo de Diplomacia Cultural do Brasil na América Latina. USP, 2015.

http://www.teses.usp.br/index.php?option=com_jumi\&fileid=9\&Itemid=159\&lang=ptbr\&id=84131\&prog=84001\&exp=0

NETO, João Pinheiro. Bons e Maus mineiros e outros brasileiros. Rio de Janeiro, ed. Mauad, 1996.

Revista Observador Económico Financiero (Hemeroteca Biblioteca Nacional)

http://memoria.bn.br/pdf/123021/per123021_1939_00047.pdf

RODRÍGUEZ AYÇAGUER, Ana Maria. La Diplomacia anticmunista: la influencia del gobierno de Getúlio Varas en la interrupción de las relaciones diplomáticas de Uruguay con la URSS en diciembre de 1935. Revista de Estudos Ibero-americanos, PUCRS, 1, Capa, v. 34, jun.2008.p 92-120. 